\title{
Five-year neurological and EEG outcome after open-heart surgery
}

\author{
KA SOTANIEMI \\ From the Department of Neurology, University of Oulu, Oulu, Finland
}

SUMMARY A five-year neurological and EEG follow-up was carried out on 55 patients who had undergone open-heart surgery for valve replacement in order to investigate the long-term results of the treatment. The five-year survival rate was $89 \%$. The prevalence of permanent neurological abnormalities after operation was $9 \%$. Transient ischaemic attacks occurred in five patients but no more severe cerebrovascular accidents were encountered. The rate of embolic events was $2 \cdot 8$ per 100 patient-years. Various subjective symptoms and complaints showed a highly beneficial outcome. Also the five-year EEG outcome was encouraging; the prevalence of abnormal EEG had fallen from the value before operation of $45 \%$ to $25 \%$. The harmful influence of long perfusion time (extracorporeal circulation) during operation was found to be reflected in the long-term EEG outcome and, significantly, not only in the patients who had, but also in those who had not developed clinical abnormalities complicating the immediate course after operation. Although a valvular surgery patient faces a number of CNS problems before, during and after operation, the overall long-term outcome of successful surgery seems highly beneficial in neurological terms.

The vast literature devoted to the central nervous system (CNS) effects of open-heart surgery has emphasised the multiplicity of potentially harmful factors to which patients are exposed before ${ }^{1-3}$ and during $^{5}$ the operation. In particular, the risks of CNS dysfunction during the operation, mostly related to extracorporeal circulation, have been thoroughly scrutinised ${ }^{6-14}$ and due to the attention paid to them they have diminished strikingly. ${ }^{4} 5$ is 16 However, cardiac surgery patients face many problems even after the correction of the major circulatory disturbance; for example they are exposed both to embolisation from the artificial valve and to the side-effects of the life-long anticoagulant therapy ${ }^{17-21}$ required with most of the types of prostheses. Thus far, neurological studies in open-heart surgery patients have been limited to describing the immediate results after operation while the later outcome has been passed over. Indeed, because most of the occasional clinical complications have been mild and reversible, investigators seem to have

Address for reprint requests: Dr KA Sotaniemi, Department of Neurology, University of Oulu, 90220 Oulu 22, Finland.

Received 20 March 1983 and in revised form 15 October 1984. Accepted 3 November 1984 been content with observing events during the critical early phase after surgery. The resultant lack of knowledge concerning the long-term course is not limited just to the clinical aspects but also includes any subclinical features of CNS abnormality. Now the major clinical problems seem to be in the process of being solved and, as investigatory methods are developed even further, the subclinical level events are being given increasing attention. Thus, 24 neuropathological, ${ }^{14}$ neuroradiological, ${ }^{25}$ biochemical ${ }^{26}{ }^{27}$ and electroencephalographical (EEG) ${ }^{1028-32}$ measures have indeed revealed postoperative CNS dysfunction even in the absence of clinical manifestations. Since the information available on the long-term neurological outcome after surgery is limited to a few brief statements in surgical reports, ${ }^{17-20}$ the present study was carried out. It is a continuation of a previous series of investigations dealing with pre- and postoperative clinical ${ }^{33}$ and $E E G^{3132}$ aspects of cardiac surgery up to the first year after surgery. The follow-up period now has been extended to 5 years.

\section{Patients and methods}

Of the 65 consecutive patients who had undergone valvular replacement surgery and clinical and EEG investiga- 
Table 1 Subjective symptoms, case histories and vocational status before and after operation.

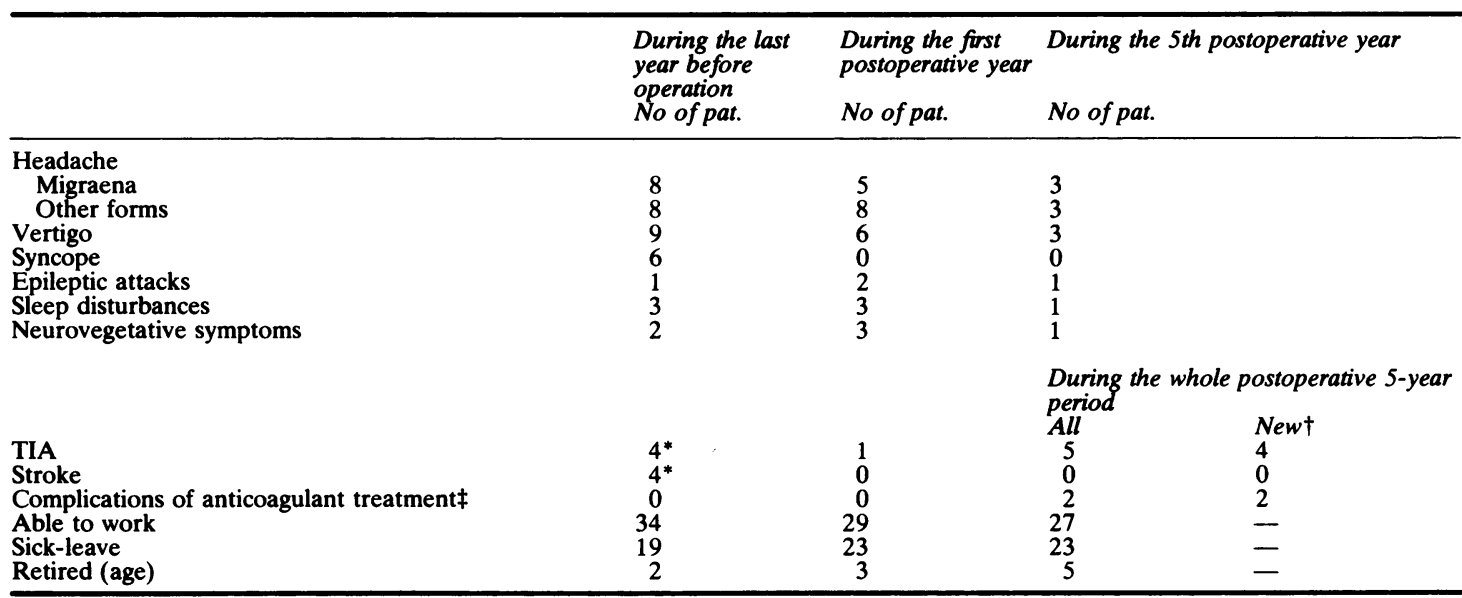

*includes all the occurrences before operation

†No of patients with no preoperative history

¥intestinal bleeding

tions before and after operation, ${ }^{3155}$ were available for re-evaluation 5 years post-operatively. Five patients had died during the first year after operation (three operative and two late deaths), and two further patients had died later of cardiac causes. There were three additional patients who did not wish to participate in the study because they had moved far away but they gave a written description of their subjective outcome, reporting good health and no neurological problems, and this information agreed with the reports given by their doctors. The case mortality rate was $8 \%$ for the first postoperative year and $3 \%$ for the following 4 years, the 5 -year survival rate thus being $89 \%$.

The timing of investigations ranged from 4 years 6 months to 5 years 9 months (mean $5.1 \pm 0.3$ years). There were 49 men and 16 women whose ages ranged from 21 to 71 (mean $46 \pm 10$ ) years. Aortic valve replacement had been performed in 40 patients, mitral valve replacement in 10 and both of the valves in five. The Björk-Shiley tilting disc prosthesis had been used in all the operations. The details of the pre-, intra- and postoperative care and arrangements have been presented previously..$^{3132}$ All the patients had a complete clinical neurological investigation performed by the author. The EEG recordings were performed using a 16-channel machine and standard conditions and four different electrode montages. The EEG recording time was at least 30 minutes. The EEG evaluation was performed using conventional methods, and using the same grading system as described in our previous reports. $^{31}{ }^{32}$

All the patients had been under regular cardiological surveillance and their optimal medication had been carefully adjusted. All had continuous anticoagulant (warfarin) therapy, the effect of which had been regularly controlled. The cardiological outcome had been assessed as optimal or highly satisfactory in all except one patient who had developed intractable cardiac failure unrelated to the pros- thesis. One further patient suffered from a declining general condition due to advanced gynaecological malignancy.

The patients were grouped according to their clinical outcome 10 days after operation: NC group (no clinical signs of CNS dysfunction) and CC group (clinical complications present). ${ }^{33}$

\section{Results}

Table 1 presents the course of the reported subjective symptoms and complaints. There was a distinct decrease in headache and vertigo. None had had syncopal attacks after operation in contrast to six cases preoperatively. Five patients had developed transient ischaemic attacks (TIA) (three carotid, two vertebrobasilar); only one of these five patients had had TIA before operation. Angiography of the precerebral vessels which was performed in the three patients with carotid symptoms (the remaining two patients refraining from the examination) showed normal findings. None of the 55 patients had developed stroke or suffered from other kinds of more severe cerebrovascular accidents (CVA).

Clinical findings Table 2 shows the clinical neurological findings. One of the five patients who had residual abnormalities related to a CVA before operation had recovered, while the preoperatively present disturbances remained unaltered in the others. The two patients who had shown motor residual signs of operative complications one year after surgery, still displayed these signs at 5 years. One additional patient who had had aphasia complicating the operation had recovered completely. Two further patients who had developed slight 
Table 2 Clinical fundings

\begin{tabular}{|c|c|c|c|}
\hline & $\begin{array}{l}\text { Before operation } \\
\text { No of pat. }\end{array}$ & $\begin{array}{l}1 \text { year after operation } \\
\text { No of pat. }\end{array}$ & $\begin{array}{l}5 \text { years after operation } \\
\text { No of pat. }\end{array}$ \\
\hline $\begin{array}{l}\text { Preoperatively present signs related to } \\
\text { preop. CVAs } \\
\text { other causes }\end{array}$ & $\begin{array}{l}5^{*} \\
6 \dagger\end{array}$ & $\begin{array}{l}3 \\
6\end{array}$ & $\begin{array}{l}3 \\
6\end{array}$ \\
\hline \multicolumn{4}{|l|}{$\begin{array}{l}\text { Residual signs of disorders developed } \\
\text { intraoperatively }\end{array}$} \\
\hline motor & - & 2 & 2 \\
\hline cognitive & - & 2 & 1 \\
\hline $\begin{array}{l}\text { peripheral } \\
\text { Renewed signs (appeared during operation, }\end{array}$ & - & 2 & $\mathbf{0}$ \\
\hline recovered within the first year) & - & - & 2 \\
\hline New signs (developed after the first postop. year) & - & - & $1 \ddagger$ \\
\hline
\end{tabular}

*one operative death included

tanisocoria 2, partial oculomotor palsy 1 , essential tremor 1 and femoral neuropathy 2

$\ddagger$ polyneuropathy in a patient who had sustained a gynaecological malignancy (treated with radiotherapy and chemotherapy)

Table 3 General EEG normality grade before and 5 years after operation.

\begin{tabular}{|c|c|c|c|c|c|}
\hline & & $\underset{N}{\text { Before operation }}$ & $\%$ & 5 years after operation & $\%$ \\
\hline All patients $\mathrm{N}=55$ & $\begin{array}{l}\text { Normal EEG } \\
\text { Abnormal EEG } \\
\text { R abnormal only } \\
\text { L abnormal only } \\
\text { both hemisph. abn. }\end{array}$ & $\begin{array}{r}30 \\
25 \\
2 \\
8 \\
15\end{array}$ & $\begin{array}{r}55 \\
45 \\
3 \\
15 \\
27\end{array}$ & $\begin{array}{r}41 \\
14 \\
0 \\
4 \\
10\end{array}$ & $\begin{array}{r}75 \\
25 \\
0 \\
7 \\
48\end{array}$ \\
\hline NC patients $N=30$ & $\begin{array}{l}\text { Normal EEG } \\
\text { Abnormal EEG } \\
\text { R abnormal only } \\
\text { L abnormal only } \\
\text { both hemisph. abn. }\end{array}$ & $\begin{array}{r}17 \\
13 \\
2 \\
4 \\
7\end{array}$ & $\begin{array}{r}57 \\
43 \\
7 \\
13 \\
23\end{array}$ & $\begin{array}{r}24 \\
6 \\
0 \\
2 \\
4\end{array}$ & $\begin{array}{r}80 \\
20 \\
0 \\
7 \\
13\end{array}$ \\
\hline$C C$ patients $N=25$ & $\begin{array}{l}\text { Normal EEG } \\
\text { Abnormal EEG } \\
\text { R abnormal only } \\
\text { L abnormal only } \\
\text { both hemisph. abn. }\end{array}$ & $\begin{array}{r}13 \\
12 \\
0 \\
4 \\
8\end{array}$ & $\begin{array}{r}52 \\
48 \\
0 \\
16 \\
27\end{array}$ & $\begin{array}{r}17 \\
8 \\
0 \\
2 \\
6\end{array}$ & $\begin{array}{r}68 \\
32 \\
0 \\
8 \\
24\end{array}$ \\
\hline
\end{tabular}

$\mathbf{R}=$ right hemisphere

$\mathrm{L}=$ left hemisphere

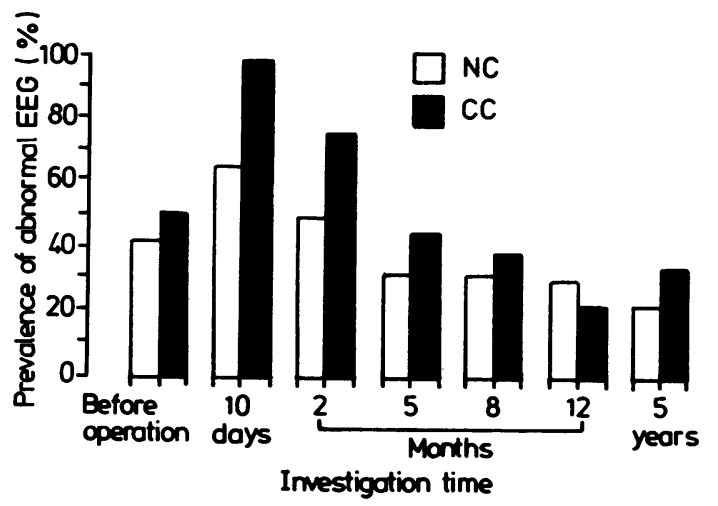

Fig 1 Follow-up of the prevalence of abnormal EEG in the patient groups with (CC) and without (NC) neurological complications present 10 days after operation. brachial plexus injury at operation and who had had residual signs at one year were now found completely normal. There were two patients who showed renewed signs, that is signs similar to those which had appeared at operation but which had disappeared within the first postoperative months.

\section{EEG results}

General EEG evaluation Table 3 gives the general normality grade of the EEG. The preoperative prevalence of abnormal EEG was $45 \%$, which contrasts with $25 \% 5$ years after operation. The left hemisphere dominated in the appearance of abnormalities both before and after operation. The proportion of bilaterally abnormal EEGs showed a slight increase, comprising $60 \%$ of the preoperative and $71 \%$ of the 5-year postoperative abnormal EEGs; 
Table 4 Mode of EEG change from the preoperative state to 5 years after operation in the cardiological groups.

\begin{tabular}{|c|c|c|c|c|c|c|c|c|}
\hline & \multicolumn{2}{|c|}{$\begin{array}{l}\text { Prevalence of abnormal EEG } \\
\text { in \% }\end{array}$} & \multicolumn{6}{|c|}{$\begin{array}{l}\text { The nature of the 5-year postoperative EEG when compared with the } \\
\text { preoperative EEG }\end{array}$} \\
\hline & \multirow{2}{*}{$\begin{array}{l}\text { Before } \\
\text { operation }\end{array}$} & \multirow{2}{*}{$\begin{array}{l}5 \text { years after } \\
\text { operation }\end{array}$} & \multicolumn{2}{|c|}{ improved } & \multicolumn{2}{|c|}{ impaired } & \multicolumn{2}{|c|}{ unchanged } \\
\hline & & & $N$ & $\%$ & $N$ & $\%$ & $N$ & $\%$ \\
\hline All (N 55) & 45 & 25 & 18 & 33 & 4 & 7 & 33 & 60 \\
\hline Aortic (N 40) & 48 & 22 & 10 & 25 & 2 & 5 & 28 & 70 \\
\hline Aortic + mitral (N 5) & 80 & 40 & 2 & 40 & 0 & 0 & 3 & 60 \\
\hline
\end{tabular}

improved/impaired: change from abnormal to normal or vice versa

this increase was due to the relatively more frequent recovery of unilateral disturbances.

The follow-up of the prevalence of abnormal EEG in the NC and CC groups is shown in fig 1. Corresponding to the clinical differences, the groups also displayed EEG differences after operation, the $\mathrm{CC}$ group experiencing EEG deterioration more often and slower recovery than the NC group. At 5 years, the $\mathrm{CC}$ group had a trend towards renewed impairment in contrast to continuing in the $\mathrm{NC}$ group. In all, 18 patients (33\%) had EEG improvement during the 5 postoperative years while four patients $(7 \%)$ had deterioration, the remaining 33 patients $(60 \%)$ remaining unaltered (table 4$)$. The respective numbers for the first year after operation had been 20,0 and 35 .

Nature of EEG abnormalities Figure 2 shows the nature of the main EEG abnormality. Theta range disturbances, which were usually episodic and appeared in the temporal regions in the great majority of cases, were the most common abnormalities both before and after operation. Slow wave abnormalities were found preoperatively and immediately

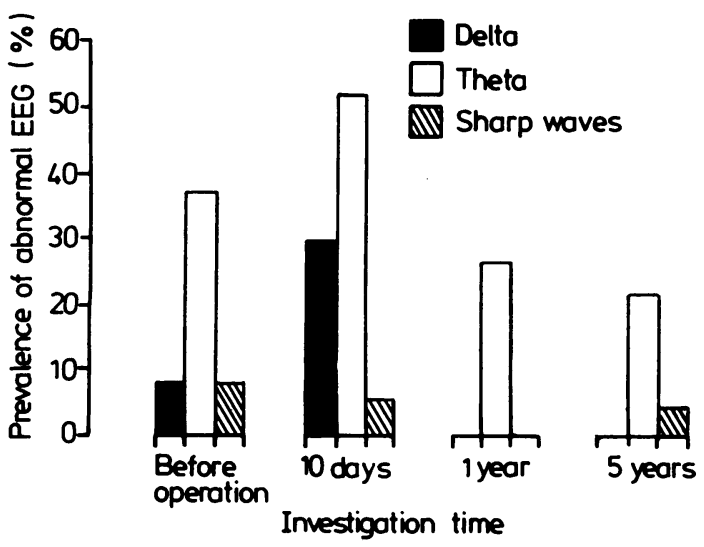

Fig 2 Nature of the main EEG abnormality before and after operation. after operation but not thereafter. Instead, sharp wave disturbances appeared at 5 years in three patients, all of whom had a clinical complication of the same hemisphere as the late EEG abnormality. Perfusion time and EEG outcome The patients were divided into a short $(<2 \mathrm{~h}$; number of patients 25 ) and a long ( $>2 \mathrm{~h}$; number of patients 30 ) perfusion time group. The prevalence of abnormal EEG fell from the preoperative value of $40 \%$ to $20 \%$ at 5 years in the short perfusion time group, in contrast to a less marked improvement from $50 \%$ in the long perfusion time group. Within the NC group, the prevalence of abnormal EEG fell from $39 \%$ to $11 \%$ in those patients whose perfusion time had been short while the change was only from $50 \%$ to $30 \%$ in those who had had a long perfusion.

Other EEG findings Age, sex, degree of valvular calcification, presence or absence of syncope or atrial fibrillation, occurrence of pre- or postoperative TIA, and the presence of residual signs related to operative complications had no detectable effect on the EEG course. Instead, differences were found between the valvular groups. During the first postoperative year, the aortic patients had a more marked EEG improvement than the mitral and multiple valvular groups. ${ }^{32}$ Thereafter, the mitral group still continued with improvement and at 5 years the proportion of the improved EEGs when compared with the preoperative state was the greatest in the mitral group (table 4).

\section{Discussion}

The observed 5-year survival of $89 \%$ (the operative and late deaths are included) compares favourably with previous studies. Ross et $^{\boldsymbol{a}^{34}} \mathbf{}^{34}$ reported a $73 \%$ 4-year survival; Björk and Henze ${ }^{17}$ an $82 \%$ survival for 5 years in aortic, $66 \%$ in mitral and $66 \%$ in aortic + mitral replacement patients; and Lewang ${ }^{20}$ reported an $86 \%$ survival rate for 7 years in aortic replacements. Thus it is concluded that our patients and the surgical and cardiological results did not differ from those in other series, despite the 
relatively high prevalence of CNS disorders after operation in the present series. ${ }^{3132}$ The importance of taking account of even the slightest degree of clinical disturbance ${ }^{35}$ is emphasised. Apart from the complications related to anticoagulant medication (table 1), treatment seemed to bring improvement in all aspects other than in the occurrence of TIA (table 1.). Serious bleeding did not occur in contrast to the 6.3 cases per 100 patient years reported previously. ${ }^{17}$ The occurrence of TIAs even exceeded the TIA prevalence observed before operation despite the continuous anticoagulant treatment. Angiography of the extracerebral vessels did not reveal any lesion in those three patients with carotid TIAs who were investigated, and the remaining two patients displayed no cervical bruits. The most probable reason was the artificial valve, as has become apparent from surgical reports. ${ }^{17}$ All the TIA patients were given additional medication with dipyridamole $(75 \mathrm{mg}$ tid). All of them have now been followed for over two additional years during which none has developed recurrent TIAs. This gives additional support to the reported ${ }^{36}$ usefulness of a combination of warfarin and dipyridamole in preventing embolism associated with prosthetic heart valves. In all, the number of embolic episodes was $2 \cdot 8 / 100$ patient-years which is in agreement with previous studies reporting rates of 2.4 episodes $/ 100$ patient-years ${ }^{37}$ with anticoagulants, and contrasts with the rates of $22 \cdot 8^{37}$ and $8 \cdot 7^{21}$ per 100 patient-years with acetylsalicylic acid + dipyridamole regimen.

Although the treatment of the prolonged cardiac disease improved many aspects of life, its effect on the vocational status was slight (table 1 ). In agreement with previous studies ${ }^{3438}$ return to work usually occurred in the first postoperative year. Neurological disturbances induced at operation contributed markedly to incapacity to work in two patients: one patient had cognitive disorders, the other patient did not recover from motor disturbances.

In previous reports ${ }^{813940}$ some preoperative factors with predictive importance have been recognised. For the present long-term results, however, only the preoperative occurrence of CVAs was found significant. Four of the five patients who had residual or renewed signs of 5 years' investigation (table 2) had a history of CVA which had occurred 1-4 years before operation. What is important is that all these patients had sustained their CVA during the period when the operative treatment was being considered, but postponed because the cardiological condition had not yet advanced to the point where the operation was thought necessary. This not only emphasises the importance of careful preoperative assessment but also indicates that more attention should be paid to the evaluation of the CNS instead of considering the heart alone.

The importance of preoperative measures may also be reflected in the EEG course of the patients. The mitral patients seemed to gain greatest postoperative EEG benefit later than the aortic patients. This might be attributed to the well-known later timing of operation in the mitral patients. This agrees with the observed differences in the course of the neuropsychological outcomes between the mitral and aortic patients. ${ }^{23}$ Thus it seems that operative treatment of valvular disease should not be postponed in patients who display coexistent factors indicating potential risks for CNS dysfunction, unless critical overriding arguments indicate the advantages of a delay.

Besides certain preoperative factors, the duration of perfusion is one of the major determinants of CNS outcome..$^{489232730-33}$ The harmful effect of long perfusion time was evident also in the longterm EEG outcome; the EEG difference between the short and long perfusion time groups was accentuated with advancing follow-up time. Significantly, the influence of perfusion time was also seen in the clinically non-affected patients and not solely in the patients who had sustained clinical complications at operation. This discloses the cumulative nature of the harmful factors effective during extracorporeal circulation and underlines the need for protecting the CNS from prolonged perfusion, the effects of which may have much widespread and long-term consequences than we have supposed so far.

The correspondence between the clinical and EEG course established immediately after operation remained also in the later course (fig 1, table 3). Impairment of the EEG when comparing the 5-year result with the preoperative EEG was observed in four patients, three of whom were $\mathrm{CC}$ cases and the remaining one NC patient appeared to be the only patient who suffered a deteriorating cardiac dysfunction. The recovery of the EEG abnormalities which appeared after operation (figs 1 and 2) reflects the mostly reversible nature of the intraoperative changes. What is most encouraging is that improvement of the basic preoperative abnormalities provides evidence that the treatment has indeed improved the cerebral circulatory and metabolic conditions.

To conclude, the postoperative process of recovery from the strains of operation and, particularly, from the prolonged circulatory disturbance, seems to be a much longer process than has been supposed thus far. Therefore, operative treatment of valvular disease should not be postponed unnecessarily. The intraoperative conditions seem to have long-term 
effects on the CNS, despite the major technical advances which have been made. Furthermore, if both optimal outcome and greater safety are desired, then consideration of the cardiological condition of the patient alone is not sufficient: closer attention must be paid to the evaluation of the CNS.

This study was supported by a grant from the Finnish Foundation for Cardiovascular Research.

\section{References}

' Kannel W, Dawber T, Cohen M, McNamara P. Vascular disease of the brain. Epidemiological aspects: The Framingham study. Am J Public Health 1965;55: 1355-66.

${ }^{2}$ Karp HR. Cerebral vascular disease and neurologic manifestations of cardiovascular disease. In: Hurst JW, ed. The Heart, 4th ed, New York, McGraw-Hill, 1978. 1890.

${ }^{3}$ Tyler HR. Neurological disorders related to congenital heart disease. In: Vinken PJ, and Bruyn GW, eds. Handbook of Clinical Neurology, vol. 38, New York, Elsevier North-Holland, 1979, 119-42.

${ }^{4}$ Mohr JP. Neurological complications of cardiac valvular disease and cardiac surgery including systemic hypotension. In: Vinken PJ, Bruyn GW, eds. Handbook of Clinical Neurology, vol. 38, New York, Elsevier North-Holland, 1979, 143-71.

${ }^{5}$ Sotaniemi KA. Neurological complications of openheart surgery. In: Silverstein A, ed. Neurological Complications of Therapy. Selected Topics. New York, Futura Press, 1982, 293-315.

${ }^{6}$ Lee WH, Brady MP, Rowe JM, Miller WC. Effects of extracorporeal circulation upon behaviour, personality and brain function. Ann Surg 1971;173:1013-23.

${ }^{7}$ Brennan RW, Patterson RH, Kessler J. Cerebral blood flow and metabolism during cardiopulmonary bypass: evidence of micro-embolic encephalopathy. Neurology (Minneap) 1971;21:665-72.

${ }^{8}$ Branthwaite MA. Neurological damage related to open-heart surgery. Thorax 1972;27:748-53.

${ }^{9}$ Frank KA, Heller SS, Kornfeld DS, Malm JR. Longterm effects of open-heart surgery in intellectual functioning. J Thorac Cardiovasc Surg 1972;64:811-15.

${ }^{10}$ Witoszka MM, Tamura H, Indeglia R, Hopkins RW, Simeone FA, et al. Electroencephalographic changes and cerebral complications in open-heart surgery. $J$ Thorac Cardiovasc Surg 1973;66:855-64.

"Carlson RG, Landé AJ, Landis B, Rogoz B, Baxter J, Patterson RH, et al. The Landé-Edwards membrane oxygenator during heart surgery. $J$ Thorac Cardiovasc Surg 1973;66:894-905.

12 Branthwaite MA. Cerebral blood flow and metabolism during open-heart surgery. Thorax 1974;29:633-8.

${ }^{13}$ Kritikou PE, Branthwaite MA. Significance of changes in cerebral electrical activity at onset of cardiopulmonary bypass. Thorax $1977 ; 32: 534-8$.

${ }^{14}$ Malone M, Prior P, Scholtz CL. Brain damage after cardiopulmonary by-pass. Correlations between neurophysiological and neuropathological findings. $J$
Neurol Neurosurg Psychiatry 1981;44:924-31.

is Kolkka R, Hilberman M. Neurologic dysfunction following cardiac operation with low-flow, low-pressure cardiopulmonary bypass. J Thorac Cardiovasc Surg 1980;79:432-7.

${ }^{16}$ Branthwaite MA. Prevention of neurological damage during open-heart surgery. Thorax 1975;30:258-61.

17 Björk VO, Henze A. Ten years' experience with the Björk-Shiley tilting disc valve. J Thorac Cardiovasc Surg 1979; 78:331-42.

${ }^{18}$ Edmiston WA, Harrison EC, Batista E, Sarma R, Kay JH, Lau FYK. Clinical experience with the Kay-Shiley mitral valve prosthesis: an eleven-year follow-up study. Scand J Thor Cardiovasc Surg 1980;14:241-7.

${ }^{19}$ Macmanus Q, Grunkemeier GL, Lambert LE, Teply JF, Harlan BJ, Starr A. Year of operation as a risk factor in the late results of valve replacement. $J$ Thorac Cardiovasc Surg 1980;80:834-41.

${ }^{20}$ Lewang OW. Aortic valve replacement. A randomized study comparing the Björk-Shiley and Lillehei-Kaster valves. Scand J Thor Cardiovasc Surg 1981;15:39-48.

${ }^{21}$ Brott WH, Zajtchuk R, Rowen RE, Davia J, Green DC. Dipyridamole-aspirin as thromboembolic prophylaxis in patients with aortic valve prosthesis. $J$ Thorac Cardiovasc Surg 1981;81:632-5.

${ }^{22}$ Gilberstadt $\mathrm{H}$, Sako $\mathrm{Y}$. Intellectual and personality changes following open-heart surgery. Arch Gen Psychiat 1967; 16:210-4.

${ }^{23}$ Sotaniemi KA, Juolasmaa A, Hokkanen TE. Neuropsychologic outcome after open-heart surgery. Arch Neurol 1981;38:2-8.

${ }^{24}$ Juolasmaa A, Outakoski J, Hirvenoja R, Tienari P, Sotaniemi KA, Takkunen J. The effect of open-heart surgery on intellectual performance. J Clin Neuropsychol 1981;3:181-7.

${ }^{25}$ Muraoka R, Yokota M, Aoshima M, Kyoku I, Nomotos, Kobayashi A, et al. Subclinical changes in brain morphology following cardiac operations as reflected by computed tomographic scans of the brain. J Thorac Cardiovasc Surg 1981;81:364-9.

${ }^{26}$ Åberg T, Ronquist G, Tydén H, Åhlund P. Release of adenylate kinase into cerebrospinal fluid during open-heart surgery and its relation to postoperative intellectual function. Lancet 1982;1:1139-42.

${ }^{27}$ Taylor KM, Devlin BJ, Mittra SM, Gillan JG, Brennan JJ, McKennan JM. Assessment of cerebral damage during open-heart surgery. A new experimental model. Scand J Thorac Cardiovasc Surg 1980;14: 197-203.

${ }^{28}$ Lorenz R, Hehrlein F. Electroencephalographic findings in heart surgery. Arch Neurol 1970;53:1069-76.

${ }^{29}$ Hansotia PL, Myers WO, Ray JF, Greehling C, Sautter RD. Prognostic value of electroencephalography in cardiac surgery. Ann Thorac Surg 1975;19:127-34.

${ }^{30}$ Sotaniemi KA, Sulg IA, Hokkanen TE. Quantitative EEG as a measure of cerebral dysfunction before and after open-heart surgery. Electroencephalogr Clin Neurophysiol 1980;50:81-95.

${ }^{31}$ Sotaniemi KA. Clinical and prognostic correlates of EEG in open-heart surgery. J Neurol Neurosurg Psychiatry 1980;43:941-7.

${ }^{32}$ Sotaniemi KA. The benefits of open-heart surgery as 
reflected in the EEG. Scand J Thorac Cardiovasc Surg 1981;15:204-12.

${ }^{33}$ Sotaniemi KA. Brain damage and neurological outcome after open-heart surgery. $J$ Neurol Neurosurg Psychiatry 1980;43:127-35.

${ }^{34}$ Ross JK, Monro JL, Diwell AE, MacKean JM, Marsh J, Barker DJP. The quality of life after cardiac surgery. Br Med J 1981;282:451-3.

${ }^{35}$ Sotaniemi KA. Cerebral outcome after extracorporeal circulation. Comparison between prospective and retrospective evaluations. Arch Neurol 1983;40:75-7.

${ }^{36}$ Sullivan JM, Harken DE, Gorlin R. Pharmacologic control of thromboembolic complications of cardiac valve replacement. N Engl J Med 1971;284:1391-4.
${ }^{37}$ Björk VO, Henze A. Management of thromboembolism after aortic valve replacement with the Björk-Shiley tilting disc valve valve. Scand J Thorac Cardiovasc Surg 1975;9:183-91.

${ }^{38}$ Blachly PH, Blachly PJ. Vocational and emotional status of 263 patients after open-heart surgery. Circulation 1968;38:524-32.

${ }^{39}$ Tufo HM, Ostfeld AM, Shekelle R. Central nervous system dysfunction following open-heart surgery. JAMA 1970;212: 1333-40.

${ }^{40}$ Sotaniemi KA. Prediction of cerebral outcome after extra-corporeal circulation. Acta Neurol Scand 1982;66:697-704. 